\title{
Relationship between glycated haemoglobin and microvascular complications: Is there a natural cut-off point for the diagnosis of diabetes?
}

\author{
C. Sabanayagam • G. Liew • E. S. Tai • A. Shankar • \\ S. C. Lim • T. Subramaniam • T. Y. Wong
}

Received: 16 December 2008/Accepted: 10 March 2009/Published online: 22 April 2009

(C) Springer-Verlag 2009

\begin{abstract}
Aims/hypothesis This study was designed to determine whether the relationship of glycated haemoglobin to diabetic microvascular complications shows any natural thresholds that could be useful in diagnosing diabetes.

Methods We examined a population-based sample of 3,190 Malay adults aged 40-80 years in Singapore. The microvascular outcomes of interest were: (1) any retinopathy,
\end{abstract}

C. Sabanayagam $\cdot$ T. Y. Wong $(\bowtie)$

Department of Ophthalmology,

Yong Loo Lin School of Medicine,

National University of Singapore,

Singapore, Singapore

e-mail: ophwty@nus.edu.sg

C. Sabanayagam $\cdot$ T. Y. Wong

Singapore Eye Research Institute,

11 Third Hospital Avenue,

Singapore 168751, Singapore

G. Liew

Centre for Vision Research, University of Sydney,

Sydney, NSW, Australia

E. S. Tai

Singapore General Hospital,

Singapore, Singapore

A. Shankar

Division of Epidemiology, Department of Community Medicine,

West Virginia University School of Medicine,

Morgantown, WV, USA

S. C. Lim $\cdot$ T. Subramaniam

Department of Medicine, Alexandra Hospital,

Singapore, Singapore

T. Y. Wong

Centre for Eye Research Australia, University of Melbourne,

Melbourne, VIC, Australia defined from fundus photographs; (2) mild retinopathy, defined as in (1); (3) moderate retinopathy, defined as in (1); (4) chronic kidney disease, defined from estimated glomerular filtration rate; (5) micro- or macroalbuminuria, defined from urinary albumin to creatinine ratio; and (6) peripheral neuropathy, defined from neurothesiometer or monofilament sensory testing.

Results Increasing $\mathrm{HbA}_{1 \mathrm{c}}$ was associated with all microvascular complications. The optimal cut-off points for detecting mild and moderate retinopathy were $6.6 \%$ (87.0\% sensitivity, $77.1 \%$ specificity and area under the receiver operating characteristics [ROC] curve 0.899) and $7.0 \%$ ( $82.9 \%$ sensitivity, $82.3 \%$ specificity and area under ROC curve 0.904). The prevalences of mild and moderate retinopathy were $<1 \%$ below the optimal cut-off points. For other complications, the association with $\mathrm{HbA}_{1 \mathrm{c}}$ was linear without evidence of a distinct threshold. Although ROC analysis for these other complications also suggested optimal cut-off points between $6.6 \%$ and $7.0 \%$, the sensitivity at these cut-off points was considerably lower than for mild and moderate retinopathy, ranging from $31.8 \%$ to $66.5 \%$.

Conclusions/interpretation Higher levels of $\mathrm{HbA}_{1 \mathrm{c}}$ were associated with microvascular complications. Our data support use of an $\mathrm{HbA}_{1 \mathrm{c}}$ cut-off point of between 6.6 and $7.0 \%$ in diagnosing diabetes. Cut-off points in this range were best for the identification of individuals with mild and moderate retinopathy. Any retinopathy, chronic kidney disease, albuminuria and peripheral neuropathy are less well detected at these cut-off points.

Keywords Chronic kidney disease - Diabetes mellitus . Glycated haemoglobin · Microalbuminuria $\cdot$ Peripheral neuropathy $\cdot$ Receiver operating characteristic curve . Retinopathy 


$\begin{array}{ll}\text { Abbreviations } \\ \text { ACR } & \text { Albumin to creatinine ratio } \\ \text { CKD } & \text { Chronic kidney disease } \\ \text { eGFR } & \text { Estimated glomerular filtration rate } \\ \text { ETDRS } & \text { Early Treatment Diabetic Retinopathy Study } \\ \text { FPG } & \text { Fasting plasma glucose } \\ \text { MDRD } & \text { Modification of Diet in Renal Disease } \\ \text { ROC } & \text { Receiver operating characteristic }\end{array}$

Introduction

Diabetes mellitus is expected to affect 300 million people by 2025 [1]. Current diagnostic criteria for diabetes are based on the concept that microvascular complications such as retinopathy and nephropathy occur above a threshold level of hyperglycaemia that can be used to differentiate people with and without diabetes [2,3]. Thus, the Expert Committee on the Diagnosis and Classification of Diabetes Mellitus [2] and World Health Organization [3] have recommended the use of a fasting plasma glucose (FPG) cut-off point of $7.8 \mathrm{mmol} / 1$ (later lowered to $7.0 \mathrm{mmol} / \mathrm{l}$ for reasons of equivalence with the $2 \mathrm{~h}$ oral glucose tolerance test for diagnosing diabetes, largely based on evidence from epidemiological studies showing that retinopathy is rare below these cut-off points but that prevalence increases dramatically above them $[2,4,5])$. However, a recent metaanalysis across three different populations found no consistent FPG threshold for retinopathy, with the data instead suggesting a continuous linear relationship and poor performance of the $7.0 \mathrm{mmol} / \mathrm{l} \mathrm{FPG}$ cut-off point in discriminating the presence of retinopathy. Such findings raise doubts about the underlying premise of a uniform glucose threshold for retinopathy [6].

Randomised controlled trials and observational studies have shown that glycated haemoglobin or haemoglobin $\mathrm{A}_{1 \mathrm{c}}$ is also a good predictor of microvascular complications [5, 7-10], is highly correlated with FPG [11] and does not require measurement in the fasting state. Thus, the use of $\mathrm{HbA}_{1 \mathrm{c}}$ as a diagnostic test for diabetes has been proposed $[12,13]$. Several studies have examined the relationship of $\mathrm{HbA}_{1 \mathrm{c}}$ to microvascular complications, but most have reported inconsistent $\mathrm{HbA}_{1 \mathrm{c}}$ thresholds. These studies were limited as most examined only one or two complications in isolation $[4,5,8,14,15]$, and all reports to date have focused on $\mathrm{HbA}_{1 \mathrm{c}}$ thresholds with the presence of retinopathy. New evidence suggests the outcome of any retinopathy is not specific to diabetic microvascular complications and that a marker of more severe microvascular damage, such as moderate retinopathy, might be more useful in deriving diagnostic thresholds for diabetes [6].
Therefore we sought to examine the evidence for an $\mathrm{HbA}_{1 \mathrm{c}}$ threshold in a population-based study with data on microvascular complications. We studied the relationship of $\mathrm{HbA}_{1 \mathrm{c}}$ to retinopathy (any, mild and moderate), chronic kidney disease (CKD), micro- and macroalbuminuria and peripheral neuropathy to determine if a natural threshold for discriminating those with and without microvascular complications exists and, if so, what the optimal $\mathrm{HbA}_{1 \mathrm{c}}$ cut-off points might be for the identification of individuals with these complications.

\section{Methods}

Study population We conducted a population-based study involving 3,280 adults of Malay ethnicity aged $40-80$ years in Singapore (78.7\% response rate). Participants were selected using an age-stratified random-sampling method from 4,168 eligible individuals, with details of the study design and methods described previously [16]. Informed written consent was obtained from all participants, and ethics approval was obtained from the Singapore Eye Research Institute institutional review board. For this study, we excluded those with missing information on $\operatorname{HbA}_{1 \mathrm{c}}(n=$ 78). Of the remaining 3,202 participants, we further excluded those with missing retinal photographs $(n=12)$, leaving 3,190 for the retinopathy analysis. Similarly, we further excluded those with missing information on serum creatinine ( $n=69$ ), leaving 3,133 for the CKD analysis. In addition, all participants with diabetes and approximately one in five randomly selected non-diabetic participants underwent assessment for peripheral neuropathy and had urine collected. For the former analyses, we included 885 participants with information on neurothesiometer readings and monofilament sensory tests; for the micro- and macroalbuminuria analysis, we included 930 participants who had information on urinary albumin to creatinine ratio (ACR).

Assessment of microvascular complications Retinopathy was assessed from digital fundus photographs taken following a standardised protocol modified from the Early Treatment Diabetic Retinopathy Study (ETDRS) [16, 17]. After pupil dilation, two photographs, centred at the optic disc (ETDRS Field 1) and macula (Field 2), were taken of both eyes of each participant using a digital retinal camera (Canon CR-DGi with a 10D SLR back; Canon, Tokyo, Japan). Photographs were then sent to the University of Sydney, Australia, and mask-graded for retinopathy and other retinal diseases [18]. Intragrader reliability of retinopathy was very high with kappa statistic of 0.98 (95\% CI 0.96-0.99) [18] GFR was estimated from serum creatinine concentration using the Modifica-tion of Diet in Renal Disease [MDRD] equation [19] defined as follows: estimated 
$\operatorname{GFR}(\mathrm{eGFR})=186.3 \times$ serum creatinine $(\mathrm{mg} / \mathrm{dl})^{-1.154} \times$ age $^{-0.203} \times(0.742$ for women $)$. To convert serum creatinine in $\mathrm{mg} / \mathrm{dl}$ to SI units ( $\mu \mathrm{mol} / \mathrm{l})$ multiply the value by 88.4 . Serum creatinine measurement was carried out at the National University Hospital Reference Laboratory, Singapore, and was reported in $\mu \mathrm{mol} / 1$. Spot untimed urine samples were collected for measurement of albumin and creatinine. Urine albumin was measured in $\mathrm{mg} / \mathrm{l}$ using a kit with a lower detection limit for albumin of $0.5 \mathrm{mg} / 1$ (Immulite, DPC, Llanberis, UK). Urine creatinine was measured in $\mathrm{mmol} / \mathrm{l}$ using a kit that uses the Jaffe reaction (Roche Diagnostics, Mannheim, Germany) with a measuring range of $0.027-32.5 \mathrm{mmol} / 1$. The ratio of urine ACR concentration expressed in $\mathrm{mg} / \mathrm{mmol}$ was used to estimate total daily albumin excretion. Vibration sense was measured in $\mathrm{V}$ at the apex of both big toes and the medial malleoli of both ankles using a neurothesiometer (Horwell, Nottingham, UK). Monofilament sensation at five different points of each foot was tested using a Touch-test Sensory Evaluator 5.07 (North Coast Medical, Morgan Hill, CA, USA). The number of points out of five at which the participant was able to sense the fine touch was recorded.

We defined seven microvascular outcomes as follows: (1) any retinopathy (severity classified based on the worse eye), defined as a severity score of level 15 and above according to a scale graded using the ETDRS adaptation of the modified Airlie House Classification System [17, 20], which corresponds to the presence of any of the following lesions: microaneurysms, haemorrhages, cotton wool spots, intraretinal microvascular abnormalities, hard exudates, venous beading and new vessels; (2) mild retinopathy, defined as a severity score above level 20 (ETDRS $>20$ ); (3) moderate retinopathy, defined as a severity score of level above 43 (ETDRS>43) [17]; (4) CKD, defined as eGFR $<60 \mathrm{ml} / \mathrm{min} / 1.73 \mathrm{~m}^{2}$, consistent with US National Kidney Foundation Kidney Disease Outcome Quality Initiative working group definition [21, 22]; (5) presence of micro- or macroalbuminuria, with microalbuminuria defined as urinary ACR $\geq 1.9 \mathrm{mg} / \mathrm{mmol}$ for men and $\geq 2.8 \mathrm{mg} / \mathrm{mmol}$ for women, and macroalbuminuria as ACR $\geq 28 \mathrm{mg} / \mathrm{mmol}$ for men and $\geq 40 \mathrm{mg} / \mathrm{mmol}$ for women [21]; (6) peripheral neuropathy, defined as either neurothesiometer reading $>25 \mathrm{~V}[23,24]$ or monofilament sensory test result below four out of five points on either side of the feet [25].

Exposure measurement All participants had $40 \mathrm{ml}$ venous blood drawn and collected in plain and fluoride oxalate tubes and stored at $4^{\circ} \mathrm{C}$ for a maximum of $4 \mathrm{~h}$ prior to processing. Serum total cholesterol, LDL- and HDLcholesterol, triacylglycerol, serum creatinine, $\mathrm{HbA}_{1 \mathrm{c}}$ and casual plasma glucose were measured at the National University Hospital Reference Laboratory, which is accredited by the College of American Pathologists. The $\mathrm{HbA}_{1 \mathrm{c}}$ assay was carried out using an HPLC cation exchange chromatography system implemented on a Biorad variant II analyser (Bio-Rad Laboratories, Hercules, CA, USA). The assay was accredited by the National Glycoprotein Standardization Program with controls traceable to the DCCT.

Information on cigarette smoking, alcohol consumption and medical history was obtained using a standardised questionnaire administered by trained personnel. Blood pressure was measured with a digital automatic blood pressure monitor after participants had been seated for at least $5 \mathrm{~min}$. Hypertension was defined as systolic blood pressure $\geq 140 \mathrm{mmHg}$ or diastolic pressure $\geq 90 \mathrm{mmHg}$ or self-reported physician-diagnosed hypertension. Diabetes mellitus was defined as a casual plasma glucose $\geq 11.1 \mathrm{mmol} / 1$ or self-reported physician-diagnosed diabetes or use of glucose-lowering medication. Body mass index was calculated as weight in kilograms divided by the square of height in meters $\left(\mathrm{kg} / \mathrm{m}^{2}\right)$. Participants were considered non-drinkers if their answer was negative to the question, 'How often do you have an alcoholic drink?' and drinkers if their answer was affirmative, irrespective of frequency and quantity. Cigarette smoking was categorised into current smoker, ex-smoker or nonsmoker.

Statistical analysis All statistical analyses were performed using SAS version 9.1 (SAS Institute, Cary, NC, USA). We compared selected baseline characteristics of the cohort by $\mathrm{HbA}_{1 \mathrm{c}}$ status, employing the $\chi^{2}$ test or analysis of variance, as appropriate. We cross-tabulated the prevalence of any retinopathy, mild retinopathy, moderate retinopathy, $\mathrm{CKD}$, micro- or macroalbuminuria and peripheral neuropathy at different $\mathrm{HbA}_{1 \mathrm{c}}$ cut-off points ranging from $5.6 \%$ to $8.0 \%$ and calculated sensitivity, specificity, positive and negative predictive values, and positive and negative likelihood ratios. We plotted the frequency of any, minimal, mild and moderate retinopathy against $\mathrm{HbA}_{1 \mathrm{c}}$ in intervals chosen to include $6.1 \%$ and $7.0 \%$. We examined these plots visually for evidence of an $\mathrm{HbA}_{1 \mathrm{c}}$ threshold above which the prevalence of any, mild and moderate retinopathy increased. We tested statistically for thresholds using change-point models, which assume a constant prevalence below the change point and a linear association above [8, 26]. To assess performance of $\mathrm{HbA}_{1 \mathrm{c}}$ in discriminating microvascular complications, we plotted receiver operating characteristic (ROC) curves and estimated the area under the curve (using the web-based calculator for ROC curves available from Johns Hopkins University, Baltimore, MD, USA [www.jrocfit.org, accessed 30 April 2008]). Finally we used logistic regression models to calculate the odds ratio and $95 \%$ confidence interval of the six microvascular 
complications across different cut-off points of $\mathrm{HbA}_{1 \mathrm{c}}$ using the lowest cut-off point as reference category in two separate models. In the first model we adjusted for age (years) and sex and in the multivariable model we additionally adjusted for body mass index $\left(\mathrm{kg} / \mathrm{m}^{2}\right)$, current smoking (absent, present), hypertension status (absent, present) and HDL-cholesterol (mmol/l). We performed tests for trends using the categories of $\mathrm{HbA}_{1 \mathrm{c}}$ as ordinal variables in multivariable logistic regression models.

\section{Results}

The baseline characteristics of the study participants are presented in Table 1. Compared with those with $\mathrm{HbA}_{1 \mathrm{c}}$ $<7 \%$, those with $\mathrm{HbA}_{1 \mathrm{c}} \geq 7.0 \%$ were significantly older, were less likely to be current smokers or drinkers, and had higher body mass index, casual plasma glucose and systolic blood pressure.

The prevalence of any retinopathy was $12.9 \%$, mild retinopathy $5.6 \%$, moderate retinopathy $3.9 \%$, CKD $21.3 \%$, micro- or macroalbuminuria $37.2 \%$ and peripheral neuropathy $21.2 \%$. Table 2 shows the relationship between $\mathrm{HbA}_{1 \mathrm{c}}$ and microvascular complications. Increasing $\mathrm{HbA}_{1 \mathrm{c}}$ categories had a higher prevalence of any retinopathy, mild retinopathy, moderate retinopathy, $\mathrm{CKD}$, micro or macroalbuminuria and peripheral neuropathy in a dose-dependent manner ( $p$ trend $<0.0001$ for any retinopathy, mild retinopathy, moderate retinopathy, CKD, micro- or macroalbuminuria and $p$ trend $=0.02$ for peripheral neuropathy). In the multivariable models, $\mathrm{HbA}_{1 \mathrm{c}}$ categories above $7.0 \%$ were significantly associated with increased prevalence of microvascular complications compared with the lowest category. In particular, persons with $\mathrm{HbA}_{1 \mathrm{c}}$ in the range $7.0-7.9 \%$ and $\geq 8.0 \%$ had ninefold and 30-fold higher prevalences of mild and moderate retinopathy than persons with $\mathrm{HbA}_{1 \mathrm{c}} \leq 6.9 \%$. The positive association between $\mathrm{HbA}_{1 \mathrm{c}}$ and the six microvascular complications persisted when $\mathrm{HbA}_{1 \mathrm{c}}$ was analysed as a continuous variable. Fig. 1 shows the cross-sectional frequency distribution of any retinopathy, mild retinopathy and moderate retinopathy by $\mathrm{HbA}_{1 \mathrm{c}}$ categories. Prevalence of any, mild and moderate retinopathy increased with increasing levels of $\mathrm{HbA}_{1 \mathrm{c}}$. The prevalence of any retinopathy at lower levels of $\mathrm{HbA}_{1 \mathrm{c}}$ was about $5 \%$ while the prevalence of mild and moderate retinopathy was almost $0 \%$ below an $\mathrm{HbA}_{1 \mathrm{c}}$ of $6.0 \%$.

Table 3 shows the prevalence of any retinopathy, mild retinopathy, moderate retinopathy, $\mathrm{CKD}$, micro- or macroalbuminuria and peripheral neuropathy above and below the various cut-off points of $\mathrm{HbA}_{1 \mathrm{c}}$ and their corresponding sensitivities, specificities, positive and negative predictive values and positive and negative likelihood ratios. The prevalence of any retinopathy below the $\mathrm{HbA}_{1 \mathrm{c}}$ cut-off point of $7.0 \%$ was $7.2 \%$ and above the cut-off point it was $35.4 \%$. The sensitivity of this cut-off point for detecting any retinopathy was $55.6 \%$, with specificity of $85.0 \%$. The positive predictive value at this cut-off point was low $(35.4 \%)$, but the negative predictive value was high (92.9\%). A higher cut-off point (8.0\%) improved specificity, positive predictive value and positive likelihood ratio, but reduced sensitivity with largely unchanged negative
Table 1 Characteristics of study participants by $\mathrm{HbA}_{1 \mathrm{c}}$ cut-off points

\footnotetext{
${ }^{\text {a }} p$ value for the difference in characteristics by $\mathrm{HbA}_{1 \mathrm{c}}$ cut-off points based on $\chi^{2}$ test or ANOVA as appropriate

${ }^{\mathrm{b}}$ Values are mean (SD)
}

\begin{tabular}{|c|c|c|c|}
\hline Characteristic & $\begin{array}{l}\mathrm{HbA}_{1 \mathrm{c}}<7.0 \% \\
(n=2,545)\end{array}$ & $\begin{array}{l}\mathrm{HbA}_{1 \mathrm{c}} \geq 7.0 \% \\
(n=645)\end{array}$ & $p$ value $\mathrm{e}^{\mathrm{a}}$ \\
\hline \multicolumn{4}{|l|}{ Age in years $(\%)$} \\
\hline $40-49$ & 28.3 & 11.8 & \multirow[t]{4}{*}{$<0.0001$} \\
\hline $50-59$ & 28.4 & 32.4 & \\
\hline $60-69$ & 21.5 & 32.3 & \\
\hline $70-81$ & 21.8 & 23.6 & \\
\hline \multicolumn{4}{|l|}{ Sex $(\%)$} \\
\hline Men & 48.7 & 44.5 & \multirow[t]{2}{*}{0.06} \\
\hline Women & 51.3 & 55.5 & \\
\hline Diabetes mellitus (\%) & 7.7 & 84.5 & $<0.0001$ \\
\hline Hypertension (\%) & 64.6 & 83.7 & $<0.0001$ \\
\hline Current cigarette smoking (\%) & 21.3 & 15.5 & 0.001 \\
\hline Alcohol consumption (\%) & 2.0 & 0.2 & 0.0009 \\
\hline Casual plasma glucose ${ }^{\mathrm{b}}(\mathrm{mmol} / \mathrm{l})$ & $5.5(1.5)$ & $11.7(5.3)$ & $<0.0001$ \\
\hline Systolic blood pressure ${ }^{\mathrm{b}}(\mathrm{mmHg})$ & $145.2(23.6)$ & $154.6(22.9)$ & $<0.0001$ \\
\hline Diastolic blood pressure $^{\mathrm{b}}(\mathrm{mmHg})$ & $79.5(11.1)$ & $80.5(11.2)$ & 0.05 \\
\hline $\mathrm{BMI}^{\mathrm{b}}\left(\mathrm{kg} / \mathrm{m}^{2}\right)$ & $26.1(5.2)$ & $27.6(4.7)$ & $<0.0001$ \\
\hline
\end{tabular}


Table 2 Association between $\mathrm{HbA}_{1 \mathrm{c}}$ and retinopathy, $\mathrm{CKD}$, albuminuria and peripheral neuropathy

\begin{tabular}{|c|c|c|c|c|}
\hline $\mathrm{HbA}_{1 \mathrm{c}}$ level $(\%)$ & No. at risk (cases) & Prevalence $(\%)$ & $\begin{array}{l}\text { Age- and sex-adjusted } \\
\text { OR }(95 \% \mathrm{CI})\end{array}$ & $\begin{array}{l}\text { Multivariable } \\
\text { OR }(95 \% \text { CI })^{\text {a }}\end{array}$ \\
\hline \multicolumn{5}{|c|}{ Any retinopathy (ETDRS scale $>15$ ) } \\
\hline$\leq 5.5$ & $700(35)$ & 5.0 & 1.00 (Referent) & 1.00 (Referent) \\
\hline $5.6-6.0$ & $1,104(61)$ & 5.5 & $1.10(0.72-1.69)$ & $1.04(0.67-1.60)$ \\
\hline $6.1-6.9$ & $741(86)$ & 11.6 & $2.40(1.59-3.62)$ & $2.20(1.44-3.35)$ \\
\hline $7.0-7.9$ & $241(57)$ & 23.7 & $5.60(3.55-8.85)$ & $4.72(2.94-7.59)$ \\
\hline$\geq 8.0$ & $404(171)$ & 42.3 & $13.39(9.02-19.90)$ & $12.01(8.01-18.02)$ \\
\hline$p$ value for trend & & & $<0.0001$ & $<0.0001$ \\
\hline One SD (1.6\%) increase & $3,190(410)$ & 12.9 & $2.08(1.91-2.27)$ & $2.03(1.86-2.22)$ \\
\hline \multicolumn{5}{|c|}{ Mild retinopathy (ETDRS scale $>20$ ) } \\
\hline$\leq 6.9$ & $2,545(32)$ & 1.3 & 1.00 (Referent) & 1.00 (Referent) \\
\hline $7.0-7.9$ & $241(28)$ & 11.6 & $9.20(5.29-16.00)$ & $9.68(5.70-16.44)$ \\
\hline$\geq 8.0$ & 404 (117) & 29.0 & $29.92(19.54-45.80)$ & $30.34(20.12-45.77)$ \\
\hline$p$ value for trend & & & $<0.0001$ & $<0.0001$ \\
\hline One SD (1.6\%) increase & $3,190(177)$ & 5.6 & $2.45(2.19-2.73)$ & $2.44(2.18-2.73)$ \\
\hline \multicolumn{5}{|c|}{ Moderate retinopathy (ETDRS scale $>43$ ) } \\
\hline$\leq 6.9$ & $2,545(21)$ & 0.8 & 1.00 (Referent) & 1.00 (Referent) \\
\hline $7.0-7.9$ & $241(16)$ & 6.6 & $7.95(4.07-15.52)$ & $8.94(4.48-17.87)$ \\
\hline$\geq 8.0$ & $404(86)$ & 21.3 & $30.45(18.60-49.86)$ & $32.31(19.16-54.47)$ \\
\hline$p$ value for trend & & & $<0.0001$ & $<0.0001$ \\
\hline One SD (1.6\%) increase & $3,190(123)$ & 3.9 & $2.38(2.12-2.68)$ & $2.36(2.09-2.66)$ \\
\hline \multicolumn{5}{|l|}{ Chronic kidney disease } \\
\hline$\leq 5.5$ & $678(80)$ & 11.8 & 1.00 (Referent) & 1.00 (Referent) \\
\hline $5.6-6.0$ & $1,089(201)$ & 18.5 & $1.54(1.15-2.08)$ & $1.45(1.07-1.96)$ \\
\hline $6.1-6.9$ & $730(189)$ & 25.9 & $1.95(1.44-2.63)$ & $1.70(1.24-2.32)$ \\
\hline $7.0-7.9$ & $240(76)$ & 31.7 & $2.50(1.71-3.66)$ & $1.98(1.34-2.94)$ \\
\hline$\geq 8.0$ & $396(122)$ & 30.8 & $2.74(1.96-3.83)$ & $2.34(1.66-3.30)$ \\
\hline$p$ value for trend & & & $<0.0001$ & $<0.0001$ \\
\hline One SD $(1.6 \%)$ increase & $3,133(668)$ & 21.3 & $1.24(1.14-1.35)$ & $1.20(1.10-1.30)$ \\
\hline \multicolumn{5}{|l|}{ Micro/macroalbuminuria } \\
\hline$<6.0$ & $547(149)$ & 27.2 & 1.00 (Referent) & 1.00 (Referent) \\
\hline $6.1-6.9$ & $218(87)$ & 39.9 & $1.51(1.07-2.14)$ & $1.31(0.91-1.88)$ \\
\hline $7.0-7.9$ & $66(34)$ & 51.5 & $2.36(1.37-4.05)$ & $1.91(1.10-3.31)$ \\
\hline$\geq 8.0$ & $99(76)$ & 76.8 & $8.36(4.99-13.96)$ & $7.52(4.45-12.72)$ \\
\hline$p$ value for trend & & & $<0.0001$ & $<0.0001$ \\
\hline One SD (1.6\%) increase & $930(346)$ & 37.2 & $2.01(1.68-2.41)$ & $1.92(1.60-2.29)$ \\
\hline \multicolumn{5}{|l|}{ Peripheral neuropathy } \\
\hline$<6.0$ & $236(37)$ & 15.7 & 1.00 (Referent) & 1.00 (Referent) \\
\hline $6.1-6.9$ & $196(39)$ & 19.9 & $1.12(0.67-1.86)$ & $1.07(0.64-1.80)$ \\
\hline $7.0-7.9$ & $151(32)$ & 21.2 & $1.25(0.73-2.13)$ & $1.57(1.02-2.42)$ \\
\hline$\geq 8.0$ & $302(80)$ & 26.5 & $1.82(1.17-2.84)$ & $1.81(1.15-2.84)$ \\
\hline$p$ value for trend & & & 0.02 & 0.02 \\
\hline One SD (1.6\%) increase & $885(188)$ & 21.2 & $1.15(1.02-1.31)$ & $1.56(1.01-1.31)$ \\
\hline
\end{tabular}

${ }^{\text {a }}$ Adjusted for age (years), sex (male, female), BMI ( $\left.\mathrm{kg} / \mathrm{m}^{2}\right)$, current smoking (absent, present), hypertension status (absent, present), HDLcholesterol (mmol/l) 
Fig. 1 Relationship between $\mathrm{HbA}_{1 \mathrm{c}}$ and any retinopathy (black bars), mild retinopathy (grey bars) and moderate retinopathy (white bars)

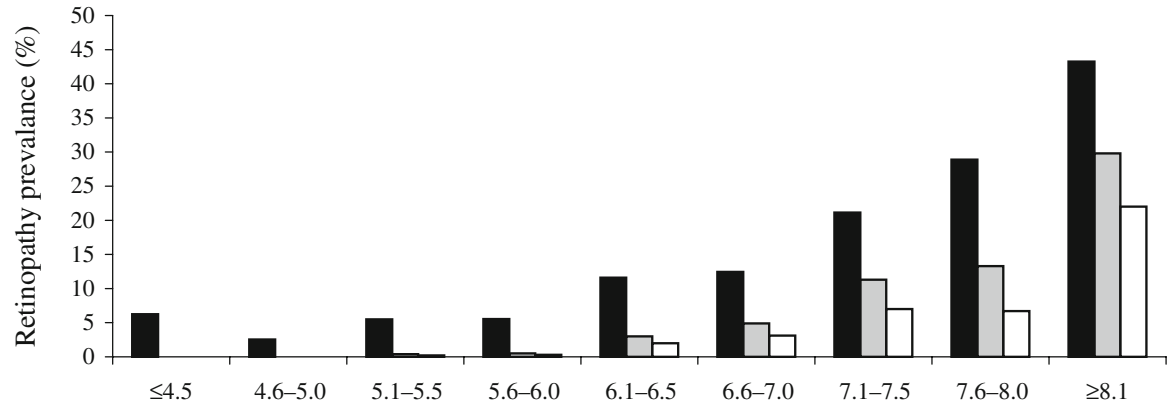

Any retinopathy Mild retinopathy Moderate retinopathy No. at risk
$\mathrm{HbA}_{1 \mathrm{c}}$ categories (\%)

$\mathrm{HoA}_{\mathrm{lc}}$ categories $(\%)$

$\begin{array}{ccc}31 & 61 & 63 \\ 2 & 5 & 16 \\ 1 & 3 & 11 \\ 566 & 1,104 & 543\end{array}$


Table 3 Sensitivity, specificity and positive and negative predictive values at different $\mathrm{HbA}_{1 \mathrm{c}}$ cut-off points for various microvascular complications

\begin{tabular}{|c|c|c|c|c|c|c|c|c|}
\hline \multirow[t]{2}{*}{$\mathrm{HbA}_{1 \mathrm{c}}(\%)$} & \multicolumn{2}{|c|}{$\begin{array}{l}\text { Number of cases/total } \\
\text { number of participants }(\%)\end{array}$} & \multirow[t]{2}{*}{$\begin{array}{l}\text { Sensitivity } \\
(\%)\end{array}$} & \multirow[t]{2}{*}{$\begin{array}{l}\text { Specificity } \\
(\%)\end{array}$} & \multirow{2}{*}{$\begin{array}{l}\text { Positive } \\
\text { predictive } \\
\text { value }(\%)\end{array}$} & \multirow{2}{*}{$\begin{array}{l}\text { Negative } \\
\text { predictive } \\
\text { value }(\%)\end{array}$} & \multirow{2}{*}{$\begin{array}{l}\text { Positive } \\
\text { likelihood } \\
\text { ratio }\end{array}$} & \multirow{2}{*}{$\begin{array}{l}\text { Negative } \\
\text { likelihood } \\
\text { ratio }\end{array}$} \\
\hline & $\begin{array}{l}\text { Below the } \\
\text { cut-off point }\end{array}$ & $\begin{array}{l}\text { Above the } \\
\text { cut-off point }\end{array}$ & & & & & & \\
\hline \multicolumn{9}{|c|}{ Any retinopathy $(n=3,190)$} \\
\hline$\geq 8.0$ & $239 / 2,786(8.6)$ & $171 / 404(42.3)$ & 41.7 & 91.6 & 42.3 & 91.4 & 5.3 & 0.6 \\
\hline$\geq 7.5$ & $211 / 2,697(6.6)$ & 199/493 (40.4) & 48.5 & 89.4 & 40.4 & 92.2 & 5.3 & 0.6 \\
\hline$\geq 7.0$ & $182 / 2,545(7.2)$ & $228 / 645(35.4)$ & 55.6 & 85.0 & 35.4 & 92.9 & 3.7 & 0.5 \\
\hline$\geq 6.5$ & $146 / 2,267(6.4)$ & $264 / 923(28.6)$ & 64.4 & 76.3 & 28.6 & 93.6 & 2.7 & 0.5 \\
\hline$\geq 6.1$ & $96 / 1,804(5.3)$ & $314 / 1,386(22.7)$ & 76.6 & 61.4 & 22.7 & 94.7 & 2.0 & 0.4 \\
\hline$\geq 5.6$ & $35 / 700(5.0)$ & $375 / 2,490(15.1)$ & 91.5 & 23.9 & 15.1 & 95.0 & 1.2 & 0.3 \\
\hline \multicolumn{9}{|c|}{ Mild retinopathy $(n=3,190)$} \\
\hline$\geq 8.0$ & $60 / 2,786(2.2)$ & $117 / 404(29.0)$ & 66.1 & 90.5 & 29.0 & 97.9 & 7.3 & 0.4 \\
\hline$\geq 7.5$ & $46 / 2,697(1.7)$ & $131 / 493(26.6)$ & 74.0 & 88.0 & 26.6 & 98.3 & 6.2 & 0.3 \\
\hline$\geq 7.0$ & $32 / 2,545(1.3)$ & $145 / 645(22.5)$ & 81.9 & 83.4 & 22.5 & 98.7 & 4.8 & 0.2 \\
\hline$\geq 6.5$ & $18 / 2,267(0.8)$ & $159 / 923(17.2)$ & 89.8 & 74.6 & 17.2 & 99.2 & 3.6 & 0.1 \\
\hline$\geq 6.1$ & $7 / 1,804(0.4)$ & $170 / 1,386(12.3)$ & 96.1 & 59.6 & 12.3 & 99.6 & 2.4 & 0.1 \\
\hline$\geq 5.6$ & 2/700 (0.3) & $175 / 2,490(7.0)$ & 98.9 & 23.2 & 7.0 & 99.7 & 1.3 & 0.0 \\
\hline \multicolumn{9}{|c|}{$\begin{array}{l}\text { Moderate retinopathy } \\
(n=3,190)\end{array}$} \\
\hline$\geq 8.0$ & $37 / 2,786(1.3)$ & $86 / 404(21.3)$ & 69.9 & 89.6 & 21.3 & 98.7 & 7.0 & 0.3 \\
\hline$\geq 7.5$ & 26/2,697 (1.1) & $94 / 493(19.1)$ & 76.4 & 87.0 & 19.1 & 98.9 & 5.8 & 0.3 \\
\hline$\geq 7.0$ & $21 / 2,545(0.8)$ & $102 / 645(15.8)$ & 82.9 & 82.3 & 15.8 & 99.2 & 4.6 & 0.2 \\
\hline$\geq 6.5$ & $10 / 2,267(0.4)$ & $113 / 923(12.2)$ & 91.9 & 73.6 & 12.2 & 99.6 & 3.5 & 0.1 \\
\hline$\geq 6.1$ & 4/1,804 (0.2) & $119 / 1,386(8.6)$ & 96.8 & 58.7 & 8.6 & 99.8 & 2.4 & 0.1 \\
\hline$\geq 5.6$ & $1 / 700(0.1)$ & $122 / 2,490(4.9)$ & 99.2 & 22.8 & 4.9 & 99.9 & 1.3 & 0.0 \\
\hline \multicolumn{9}{|c|}{$\begin{array}{l}\text { Chronic kidney disease } \\
(n=3,133)\end{array}$} \\
\hline$\geq 8.0$ & $546 / 2,737(20.0)$ & $122 / 396(30.8)$ & 18.3 & 88.9 & 30.8 & 80.1 & 1.6 & 0.9 \\
\hline$\geq 7.5$ & $518 / 2,649(19.6)$ & $150 / 484(31.0)$ & 22.5 & 86.5 & 31.0 & 80.5 & 1.8 & 0.9 \\
\hline$\geq 7.0$ & 470/2,497 (18.8) & $198 / 636(31.1)$ & 29.6 & 82.2 & 31.1 & 81.2 & 1.7 & 0.9 \\
\hline$\geq 6.5$ & $397 / 2,225(17.8)$ & 271/908 (29.9) & 40.6 & 74.2 & 29.9 & 82.2 & 1.6 & 0.8 \\
\hline$\geq 6.1$ & 281/1,767 (15.9) & $387 / 1,366(28.3)$ & 57.9 & 60.3 & 28.3 & 84.1 & 1.5 & 0.7 \\
\hline$\geq 5.6$ & 80/678 (11.8) & $588 / 2,455(24.0)$ & 88.0 & 24.3 & 24.0 & 88.2 & 1.2 & 0.5 \\
\hline \multicolumn{9}{|c|}{$\begin{array}{l}\text { Micro- and } \\
\text { macroalbuminuria }(n=930)\end{array}$} \\
\hline$\geq 8.0$ & $270 / 831(32.5)$ & 76/99 (76.8) & 22.0 & 96.1 & 76.8 & 67.5 & 5.5 & 0.8 \\
\hline$\geq 7.5$ & 257/806 (31.9) & 89/124(71.8) & 25.7 & 94.0 & 71.8 & 68.1 & 4.3 & 0.8 \\
\hline$\geq 7.0$ & $236 / 765(30.9)$ & $110 / 165(66.7)$ & 31.8 & 90.6 & 66.7 & 69.2 & 3.6 & 0.7 \\
\hline$\geq 6.5$ & 203/687 (29.6) & $143 / 243(58.9)$ & 41.3 & 82.9 & 58.9 & 70.5 & 2.4 & 0.7 \\
\hline$\geq 6.1$ & $149 / 547(27.2)$ & $197 / 383(51.4)$ & 56.9 & 68.2 & 51.4 & 72.8 & 1.8 & 0.6 \\
\hline$\geq 5.6$ & 49/205 (23.9) & $297 / 725(41.0)$ & 85.8 & 27.7 & 41.0 & 76.1 & 1.2 & 0.5 \\
\hline \multicolumn{9}{|c|}{$\begin{array}{l}\text { Peripheral neuropathy } \\
(n=885)\end{array}$} \\
\hline$\geq 8.0$ & $108 / 583(18.5)$ & $80 / 302(26.5)$ & 42.6 & 68.2 & 26.5 & 81.5 & 1.3 & 0.8 \\
\hline$\geq 7.5$ & 93/521 (17.9) & $95 / 364(26.1)$ & 50.5 & 61.4 & 26.1 & 82.2 & 1.3 & 0.8 \\
\hline$\geq 7.0$ & $76 / 432(17.6)$ & $112 / 453(24.7)$ & 59.6 & 51.1 & 24.7 & 82.4 & 1.2 & 0.8 \\
\hline$\geq 6.5$ & $54 / 324(16.7)$ & $134 / 561(23.9)$ & 71.3 & 38.7 & 23.9 & 83.3 & 1.2 & 0.7 \\
\hline$\geq 6.1$ & $37 / 236(15.6)$ & $151 / 649(23.2)$ & 80.3 & 28.6 & 23.3 & 84.3 & 1.1 & 0.7 \\
\hline$\geq 5.6$ & $16 / 86(18.6)$ & $172 / 799(21.5)$ & 91.5 & 10.0 & 21.5 & 81.4 & 1.0 & 0.8 \\
\hline
\end{tabular}


Several studies indicate that $\mathrm{HbA}_{1 \mathrm{c}}$ may show a glycaemic threshold with microvascular complications, suggesting it may additionally be useful as a diagnostic test for diabetes $[12,29]$. In this population-based study of over 3,000 middle-aged individuals, we found a linear continuous relationship of $\mathrm{HbA}_{1 \mathrm{c}}$ with microvascular complications including any retinopathy, mild retinopathy, moderate retinopathy, $\mathrm{CKD}$, micro- or macroalbuminuria and peripheral neuropathy. We found no evidence for a threshold effect of $\mathrm{HbA}_{1 \mathrm{c}}$ with any retinopathy, micro- or macroalbuminuria, CKD and peripheral neuropathy. However, there was a clear difference in the relationship of $\mathrm{HbA}_{1 \mathrm{c}}$ to mild and moderate retinopathy compared with other microvascular complications (any retinopathy, albuminuria, CKD and peripheral neuropathy). Mild and moderate retinopathy were rare below $\mathrm{HbA}_{1 \mathrm{c}}$ 6.6-7.0\% and the prevalence increased 16-17-fold above this level of $\mathrm{HbA}_{1 \mathrm{c}}$. For mild and moderate retinopathy, the areas under ROC curves for $\mathrm{HbA}_{1 \mathrm{c}}$ were 0.899 and 0.904 and the optimal cutoff points maximising sensitivity and specificity were $6.6 \%$ and $7.0 \%$. Several other observations support the validity of using mild and moderate retinopathy, rather than any retinopathy, as specific glycaemic markers for diabetesthe almost complete absence of mild and moderate retinopathy below an $\mathrm{HbA}_{1 \mathrm{c}}$ level of $6.6-7.0 \%$, and the lack of association of hypertension and dyslipidaemia with mild and moderate retinopathy. In contrast, prevalences of microvascular complications other than mild and moderate retinopathy were high below $\mathrm{HbA}_{1 \mathrm{c}} 7.0 \%$ (7.2\% for any retinopathy, $18.8 \%$ for $\mathrm{CKD}, 30.9 \%$ for micro- or macroalbuminuria and $17.6 \%$ for peripheral neuropathy). Analysis of the ROC curves suggested that an $\mathrm{HbA}_{1 \mathrm{c}}$ cut-off point of between 6.6 and $7.0 \%$ optimised sensitivity and specificity for identifying individuals with these other complications, consistent with the optimal cut-off points identified for mild and moderate retinopathy. However, sensitivity at these optimal cut-off points was considerably lower than for mild and moderate retinopathy, ranging from $31.8 \%$ to $66.5 \%$ depending on the complication.

The $\mathrm{HbA}_{1 \mathrm{c}}$ thresholds for increasing prevalence of any retinopathy were reported to be between $6.1 \%$ and $7.0 \%$ in studies conducted among different ethnic groups $[2,4,5$, 8]. Few epidemiological studies have examined the optimal cut-off points for $\mathrm{HbA}_{1 \mathrm{c}}$ that maximise sensitivity and specificity. In Pima Indians, the optimal $\mathrm{HbA}_{1 \mathrm{c}}$ cut-off point of $7.0 \%$ had $78.1 \%$ sensitivity and $84.7 \%$ specificity for detecting any retinopathy [5]. In the Hisayama study, the optimal $\mathrm{HbA}_{1 \mathrm{c}}$ cut-off point of $5.7 \%$ was reported to have a sensitivity of $86.5 \%$ with a specificity of $90.1 \%$ [14]. The variability in optimal cut-off points could be due to assay differences in measuring $\mathrm{HbA}_{1 \mathrm{c}}$. Other reasons for the variability in optimal cut-off points could be the different ethnicities, age and sex distribution and prevalence of diabetes [29]. It should be noted that the Meta-analysis Research Group on the Diagnosis of Diabetes Using Glycated Hemoglobin levels has recommended an $\mathrm{HbA}_{1 \mathrm{c}}$ cut-off point of $\geq 7.0 \%$ [30], which agrees well with our findings.

Our findings of a continuous relationship of $\mathrm{HbA}_{1 \mathrm{c}}$ to microvascular complications without any evidence of a clear threshold effect for most of the microvascular complications examined is consistent with a recent metaanalysis that showed a similar lack of fasting glucose thresholds with retinopathy [6]. Other studies have also documented a continuous association between FPG and CKD [31], microalbuminuria [32] and peripheral neuropathy $[33,34]$. Taken together, these results argue against the existence of glycaemic thresholds for the majority of microvascular complications. Given the lack of a distinct glycaemic threshold for most microvascular complications, it is not surprising that the areas under the ROC curves were modest, ranging from 0.573 for peripheral neuropathy to 0.754 for any retinopathy.

Several factors could explain these findings. First, any retinopathy [6, 35-37], and nephropathy [38, 39] may also occur in persons without diabetes as these outcomes are related to non-glycaemic processes such as age, obesity, dyslipidaemia and hypertension [40,41], which are very common in the population. As such, it should not be surprising that some of these complications that are not specific to hyperglycaemia are seen at the relatively low levels of glycaemia observed in this study. Second, $\mathrm{HbA}_{1 \mathrm{c}}$ was measured at a single time-point, and we did not collect information on previous glycaemia levels, which have been shown to have an impact on the risk of microvascular complications [42-44] and may influence the prevalence of microvascular complications. Unlike in trials of intensive glycaemic control, most of our participants with $\mathrm{HbA}_{1 \mathrm{c}}$ below $7.0 \%$ did not have previously diagnosed diabetes ( $7 \%$ had previously diagnosed diabetes below $\mathrm{HbA}_{1 \mathrm{c}}=7 \%$ ) and were therefore not receiving pharmacological treatment or even therapeutic lifestyle modification to lower blood glucose. We do not believe that, in these circumstances, large changes in glycaemia are likely to have occurred prior to their participation in this study, certainly not of the magnitude seen in the interventional trials. Furthermore, excluding participants on glucose-lowering medication did not change our results appreciably.

The main strengths of our study are its population-based sample, our precise estimation of any, mild and moderate retinopathy, and the inclusion of data on other microvascular endpoints collected using standardised protocols. In addition, $\mathrm{HbA}_{1 \mathrm{c}}$ was measured according to internationally accepted standards.

Limitations of this study should also be noted. First, we did not have information on FPG, and were unable to compare the performance of $\mathrm{HbA}_{1 \mathrm{c}}$ against FPG as a 


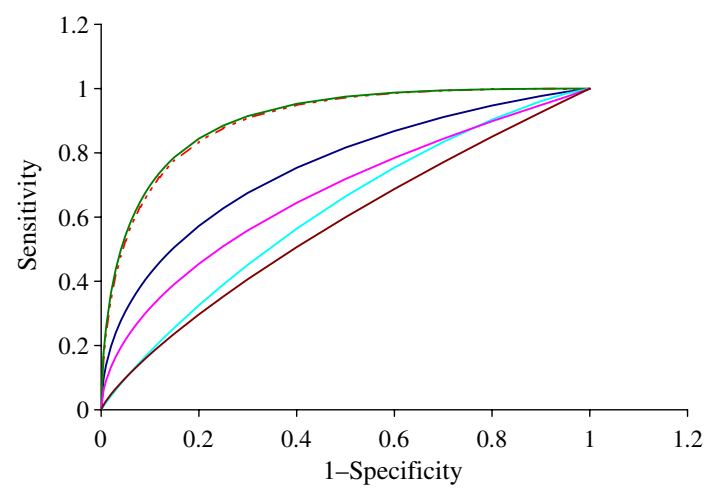

Fig. 2 ROC curves for $\mathrm{HbA}_{1 \mathrm{c}}(\%)$ and the various microvascular complications. AUC for any retinopathy (dark blue line) 0.754; AUC for mild retinopathy 0.899 (dashed red line); AUC for moderate retinopathy (green line) 0.904; AUC for chronic kidney disease (light blue line) 0.615; AUC for micro- and macroalbuminuria (pink line) 0.673; AUC for peripheral neuropathy (brown line) 0.573

diagnostic test for diabetes. This was not the aim of the study and requires further investigation. Second, we took a single measurement of $\mathrm{HbA}_{1 \mathrm{c}}$, which could potentially misclassify chronic glucose exposure. We obtained similar results with an alternative glycaemic measure (casual plasma glucose) suggesting this potential misclassification would not have influenced our conclusions. Third, this was a cross-sectional study and we are thus unable to determine the relationship of $\mathrm{HbA}_{1 \mathrm{c}}$ to incident microvascular outcomes. Follow-up of the study population is currently in progress. Fourth, we examined micro- and macroalbuminuria and peripheral neuropathy in only a sample of participants. Fifth, we obtained photographs of two central retinal fields, which is less sensitive than using seven retinal fields; however, this is unlikely to introduce much bias as most diabetic retinopathy, particular mild and moderate retinopathy, occurs in those two fields [45]. Finally, the study was performed in a homogeneous Malay population, and requires confirmation in other ethnic groups and more ethnically heterogeneous populations. However, the racial homogeneity of the study population offers the advantage of precluding confounding by race.

The current American Diabetes Association and WHO guidelines for diagnosing diabetes do not take $\mathrm{HbA}_{1 \mathrm{c}}$ into account and are based on FPG, casual blood glucose and OGTTs. This is despite the many advantages to using $\mathrm{HbA}_{1 \mathrm{c}}$ over other glycaemic measures such as less intraindividual variation [29], good ability to detect undiagnosed diabetes [46, 47] and predict risk of developing microvascular complications both in type 1 and type 2 diabetes [9, $10,48]$, and widespread acceptance as a common endpoint in clinical trials. Our study suggests that $\mathrm{HbA}_{1 \mathrm{c}}$ may be a useful measure for diagnosing diabetes and supports a possible cut-off point at between $6.6 \%$ and $7.0 \%$, which is in line with current recommendations [12, 13, 30, 47]. It should, however, be noted that thresholds within this range are particularly useful for the identification of mild and moderate retinopathy rather than other complications. This may be appropriate for the prevention of retinal disease associated with hyperglycaemia as previous longitudinal studies conducted in diabetic patients have demonstrated little development or progression of retinopathy or overt proteinuria if mean $\mathrm{HbA}_{1 \mathrm{c}}$ level is maintained below 7.0\% [48-50]. Thus, failure to detect a significant proportion of individuals with earlier forms of retinopathy may not be critical to the prevention of visual loss, as long as $\mathrm{HbA}_{1 \mathrm{c}}$ remains below $7.0 \%$. With regards to the other microvascular complications associated with hyperglycaemia, it appears that there is poor, or limited, support for a discrete inflection point that can be used for diagnostic purposes. However, high $\mathrm{HbA}_{1 \mathrm{c}}$ levels were still positively associated with microvascular complications (e.g. those with an $\mathrm{HbA}_{1 \mathrm{c}}$ level above $8 \%$ were seven times as likely to have micro- or macroalbuminuria than those with an $\mathrm{HbA}_{1 \mathrm{c}}$ below 6\%). An area of future research is comparing the performance of $\mathrm{HbA}_{1 \mathrm{c}}$ with that of other measures of glycaemia such as FPG or oral glucose tolerance test in dichotomising these microvascular complications.

In conclusion, we report a continuous linear association between $\mathrm{HbA}_{1 \mathrm{c}}$ and microvascular complications, including any, mild and moderate retinopathy, $\mathrm{CKD}$, micro- and macroalbuminuria and peripheral neuropathy without any clear and consistent threshold effect across the different outcomes. Despite the lack of an abrupt threshold, $\mathrm{HbA}_{1 \mathrm{c}}$ cut-off points in the range 6.6 to $7.0 \%$ were optimal for detecting microvascular complications and performed well

Table 4 Optimal cut-off points of $\mathrm{HbA}_{1 \mathrm{c}}$ for the detection of microvascular complications as defined by maximising sensitivity and specificity

\begin{tabular}{|c|c|c|c|c|c|}
\hline Microvascular complication & Optimal cut-off point (\%) & Sensitivity (\%) & Specificity (\%) & Accuracy $(\%)$ & ROC curve area \\
\hline Any retinopathy & 7.0 & 55.6 & 85.0 & 81.2 & 0.754 \\
\hline Mild retinopathy & 6.6 & 87.0 & 77.1 & 77.7 & 0.899 \\
\hline Moderate retinopathy & 7.0 & 82.9 & 82.3 & 82.3 & 0.904 \\
\hline Chronic kidney disease & 6.6 & 37.9 & 76.6 & 68.4 & 0.615 \\
\hline Micro- and macroalbuminuria & 7.0 & 31.8 & 90.6 & 54.8 & 0.673 \\
\hline Peripheral neuropathy & 6.6 & 66.5 & 41.5 & 46.8 & 0.573 \\
\hline
\end{tabular}


at discriminating presence of mild and moderate retinopathy. Together with the significant advantages of $\mathrm{HbA}_{1 \mathrm{c}}$ over other glycaemic measures, for example, no requirement of fasting, less variability, consistent associations with microand macrovascular complications, and improved international standardisation of measurement, our data support use of an $\mathrm{HbA}_{1 \mathrm{c}}$ cut-off point between $6.6 \%$ and $7.0 \%$ in diagnosing diabetes. However, it will be important to examine the impact of using alternative tests of glycaemia, or other diagnostic strategies, to identify those with microvascular complications. The public health impact of such strategies should also be carefully examined as the detection of these complications early will have an impact on healthcare resource use and the benefits of such early detection must be clearly delineated.

Acknowledgements The authors thank the staff and participants in the Singapore Malay Eye Study for their important contributions. The authors also thank P. Chen, Department of Statistics and Applied Probability, National University of Singapore, for her help with the figures. This study was supported by National Medical Research Council grants 0796/2003, IRG07nov013 and STaR/0003/2008.

Duality of interest The authors declare that there is no duality of interest associated with this manuscript.

\section{References}

1. King H, Aubert RE, Herman WH (1998) Global burden of diabetes, 1995-2025: prevalence, numerical estimates, and projections. Diabetes Care 21:1414-1431

2. Anonymous (2003) Report of the expert committee on the diagnosis and classification of diabetes mellitus. Diabetes Care 26(Suppl 1):S5-S20

3. World Health Organization (2008) Definition and diagnosis of diabetes mellitus and intermediate hyperglycemia. Available from www.who.int/diabetes/publications/en/, accessed 5 August 2008

4. Engelgau MM, Thompson TJ, Herman WH et al (1997) Comparison of fasting and 2-hour glucose and HbAlc levels for diagnosing diabetes. Diagnostic criteria and performance revisited. Diabetes Care 20:785-791

5. McCance DR, Hanson RL, Charles MA et al (1994) Comparison of tests for glycated haemoglobin and fasting and two hour plasma glucose concentrations as diagnostic methods for diabetes. BMJ 308:1323-1328

6. Wong TY, Liew G, Tapp RJ et al (2008) Relation between fasting glucose and retinopathy for diagnosis of diabetes: three population-based cross-sectional studies. Lancet 371:736-743

7. American Diabetes Association (2007) Standards of medical care in diabetes-2007. Diabetes Care 30:S4-S41

8. Tapp RJ, Zimmet PZ, Harper CA et al (2006) Diagnostic thresholds for diabetes: the association of retinopathy and albuminuria with glycaemia. Diabetes Res Clin Pract 73:315-321

9. Anonymous (1993) The effect of intensive treatment of diabetes on the development and progression of long-term complications in insulin-dependent diabetes mellitus. The diabetes control and complications trial research group. N Engl J Med 329:977-986

10. Anonymous (1998) Intensive blood-glucose control with sulphonylureas or insulin compared with conventional treatment and risk of complications in patients with type 2 diabetes (UKPDS 33).
UK Prospective Diabetes Study (UKPDS) Group. Lancet 352:837-853

11. Ito C, Maeda R, Ishida S, Sasaki H, Harada H (2000) Correlation among fasting plasma glucose, two-hour plasma glucose levels in OGTT and HbA1c. Diabetes Res Clin Pract 50:225-230

12. Saudek CD, Herman WH, Sacks DB, Bergenstal RM, Edelman D, Davidson MB (2008) A new look at screening and diagnosing diabetes mellitus. J Clin Endocrinol Metab 93:2447-2453

13. Barr RG, Nathan DM, Meigs JB, Singer DE (2002) Tests of glycemia for the diagnosis of type 2 diabetes mellitus. Ann Intern Med 137:263-272

14. Miyazaki M, Kubo M, Kiyohara Y et al (2004) Comparison of diagnostic methods for diabetes mellitus based on prevalence of retinopathy in a Japanese population: the Hisayama Study. Diabetologia 47:1411-1415

15. Klein R, Klein BE, Moss SE (1996) Relation of glycemic control to diabetic microvascular complications in diabetes mellitus. Ann Intern Med 124:90-96

16. Foong AW, Saw SM, Loo JL et al (2007) Rationale and methodology for a population-based study of eye diseases in Malay people: the Singapore Malay Eye Study (SiMES). Ophthalmic Epidemiol 14:25-35

17. Wong TY, Cheung N, Tay WT et al (2008) Prevalence and risk factors for diabetic retinopathy the Singapore Malay Eye Study. Ophthalmology 15:1869-1875

18. Mitchell P, Smith W, Wang JJ, Attebo K (1998) Prevalence of diabetic retinopathy in an older community. The Blue Mountains Eye Study. Ophthalmology 105:406-411

19. Levey AS, Bosch JP, Lewis JB, Greene T, Rogers N, Roth D (1999) A more accurate method to estimate glomerular filtration rate from serum creatinine: a new prediction equation. Modification of Diet in Renal Disease Study Group. Ann Intern Med 130:461-470

20. Anonymous (1991) Grading diabetic retinopathy from stereoscopic color fundus photographs - an extension of the modified Airlie House classification. ETDRS report number 10. Early Treatment Diabetic Retinopathy Study Research Group. Ophthalmology 98:786-806

21. Anonymous (2002) K/DOQI clinical practice guidelines for chronic kidney disease: evaluation, classification, and stratification. Am J Kidney Dis 39:S1-266

22. Shankar A, Leng C, Chia KS et al (2008) Association between body mass index and chronic kidney disease in men and women: population-based study of Malay adults in Singapore. Nephrol Dial Transplant 23:1910-1918

23. Young MJ, Every N, Boulton AJ (1993) A comparison of the neurothesiometer and biothesiometer for measuring vibration perception in diabetic patients. Diabetes Res Clin Pract 20:129131

24. O'Neill J, McCann SM, Lagan KM (2006) Tuning fork (128 Hz) vs neurothesiometer: a comparison of methods of assessing vibration sensation in patients with diabetes mellitus. Int J Clin Pract 60:174-178

25. Kumar S, Fernando DJ, Veves A, Knowles EA, Young MJ, Boulton AJ (1991) Semmes-Weinstein monofilaments: a simple, effective and inexpensive screening device for identifying diabetic patients at risk of foot ulceration. Diabetes Res Clin Pract 13:6367

26. Ulm K (1991) A statistical method for assessing a threshold in epidemiological studies. Stat Med 10:341-349

27. Nathan DM, Turgeon H, Regan S (2007) Relationship between glycated haemoglobin levels and mean glucose levels over time. Diabetologia 50:2239-2244

28. Saudek CD, Derr RL, Kalyani RR (2006) Assessing glycemia in diabetes using self-monitoring blood glucose and hemoglobin A1c. JAMA 295:1688-1697 
29. Bennett CM, Guo M, Dharmage SC (2007) $\mathrm{HbA}(1 \mathrm{c})$ as a screening tool for detection of Type 2 diabetes: a systematic review. Diabet Med 24:333-343

30. Peters AL, Davidson MB, Schriger DL, Hasselblad V (1996) A clinical approach for the diagnosis of diabetes mellitus: an analysis using glycosylated hemoglobin levels. Meta-analysis research group on the diagnosis of diabetes using glycated hemoglobin levels. JAMA 276:1246-1252

31. Fox CS, Larson MG, Leip EP, Meigs JB, Wilson PW, Levy D (2005) Glycemic status and development of kidney disease: the Framingham Heart Study. Diabetes Care 28:2436-2440

32. Mykkanen L, Haffner SM, Kuusisto J, Pyorala K, Laakso M (1994) Microalbuminuria precedes the development of NIDDM. Diabetes 43:552-557

33. Ziegler D, Rathmann W, Dickhaus T, Meisinger C, Mielck A (2008) Prevalence of polyneuropathy in pre-diabetes and diabetes is associated with abdominal obesity and macroangiopathy: the MONICA/KORA Augsburg Surveys S2 and S3. Diabetes Care 31:464-469

34. Polydefkis M, Griffin JW, McArthur J (2003) New insights into diabetic polyneuropathy. JAMA 290:1371-1376

35. Chao JR, Lai MY, Azen SP, Klein R, Varma R (2007) Retinopathy in persons without diabetes: the Los Angeles Latino Eye Study. Invest Ophthalmol Vis Sci 48:4019-4025

36. Wong TY, Barr EL, Tapp RJ et al (2005) Retinopathy in persons with impaired glucose metabolism: the Australian Diabetes Obesity and Lifestyle (AusDiab) study. Am J Ophthalmol 140:1157-1159

37. Kawasaki R, Wang JJ, Wong TY, Kayama T, Yamashita H (2008) Impaired glucose tolerance, but not impaired fasting glucose, is associated with retinopathy in Japanese population: the Funagata study. Diabetes Obes Metab 10:514-515

38. Gerstein HC, Pogue J, Mann JF et al (2005) The relationship between dysglycaemia and cardiovascular and renal risk in diabetic and non-diabetic participants in the HOPE study: a prospective epidemiological analysis. Diabetologia 48:1749-1755

39. Haffner SM, Gonzales C, Valdez RA et al (1993) Is microalbuminuria part of the prediabetic state? The Mexico City Diabetes Study. Diabetologia 36:1002-1006
40. Yu T, Mitchell P, Berry G, Li W, Wang JJ (1998) Retinopathy in older persons without diabetes and its relationship to hypertension. Arch Ophthalmol 116:83-89

41. Miljanovic B, Glynn RJ, Nathan DM, Manson JE, Schaumberg DA (2004) A prospective study of serum lipids and risk of diabetic macular edema in type 1 diabetes. Diabetes 53:28832892

42. Anonymous (2002) Effect of intensive therapy on the microvascular complications of type 1 diabetes mellitus. JAMA 287:25632569

43. Anonymous (2003) Sustained effect of intensive treatment of type 1 diabetes mellitus on development and progression of diabetic nephropathy: the Epidemiology of Diabetes Interventions and Complications (EDIC) study. JAMA 290:2159-2167

44. Gaede P, Lund-Andersen H, Parving HH, Pedersen O (2008) Effect of a multifactorial intervention on mortality in type 2 diabetes. N Engl J Med 358:580-591

45. Moss SE, Meuer SM, Klein R, Hubbard LD, Brothers RJ, Klein BE (1989) Are seven standard photographic fields necessary for classification of diabetic retinopathy? Invest Ophthalmol Vis Sci 30:823-828

46. Edelman D, Olsen MK, Dudley TK, Harris AC, Oddone EZ (2004) Utility of hemoglobin A1c in predicting diabetes risk. J Gen Intern Med 19:1175-1180

47. Rohlfing CL, Little RR, Wiedmeyer HM et al (2000) Use of GHb $(\mathrm{HbA1c})$ in screening for undiagnosed diabetes in the U.S. population. Diabetes Care 23:187-191

48. Anonymous (1995) The relationship of glycemic exposure (HbAlc) to the risk of development and progression of retinopathy in the diabetes control and complications trial. Diabetes 44:968-983

49. Ohkubo Y, Kishikawa H, Araki E et al (1995) Intensive insulin therapy prevents the progression of diabetic microvascular complications in Japanese patients with non-insulin-dependent diabetes mellitus: a randomized prospective 6-year study. Diabetes Res Clin Pract 28:103-117

50. Warram JH, Scott LJ, Hanna LS et al (2000) Progression of microalbuminuria to proteinuria in type 1 diabetes: nonlinear relationship with hyperglycemia. Diabetes 49:94-100 